Open Ocean • Here be Dragons 2018

\title{
Connected Coral Report
}

Emily Salvador ${ }^{1}$ Nina Lutz $^{1}$

${ }^{1}$ MIT Media Lab

Published on: Oct 01, 2021

DOI: https://doi.org/10.21428/a680be9a.207c346e/4f361cef

License: Creative Commons Attribution 4.0 International License (CC-BY 4.0). 


\section{Challenge}

Through the Here Be Dragons Conference, we noticed that while compelling research is actively conducted, creating amazing data and footage, there is still a need to convey that information to the public in more engaging ways. We proposed a triptych of experiences ranging from the macro to micro scale. In Connected Coral, we focused on the projection-mapped coral reef display.

\section{Approach}

Connected Coral integrates physical and digital elements in a visualization of the environmental impacts on reefs. This complex projection mapping uses multiple projectors, angled mirrors, and a motion sensor to create an interactive digital skin on a complex three-dimensional surface. Users can use multiple hands to interact with the animation by bringing a bleached coral reef back to life.

The physical coral model was fabricated at scale based on photogrammetry scans of real coral. These scans were provided by The Hydrous, a nonprofit organization for ocean exploration. The scan was taken through a computational script in order to be sectioned into slabs that preserved as much of the geometry as possible. These slabs were fabricated on a CNC Router using insulation foam. The slabs were then joined together and painted white. 


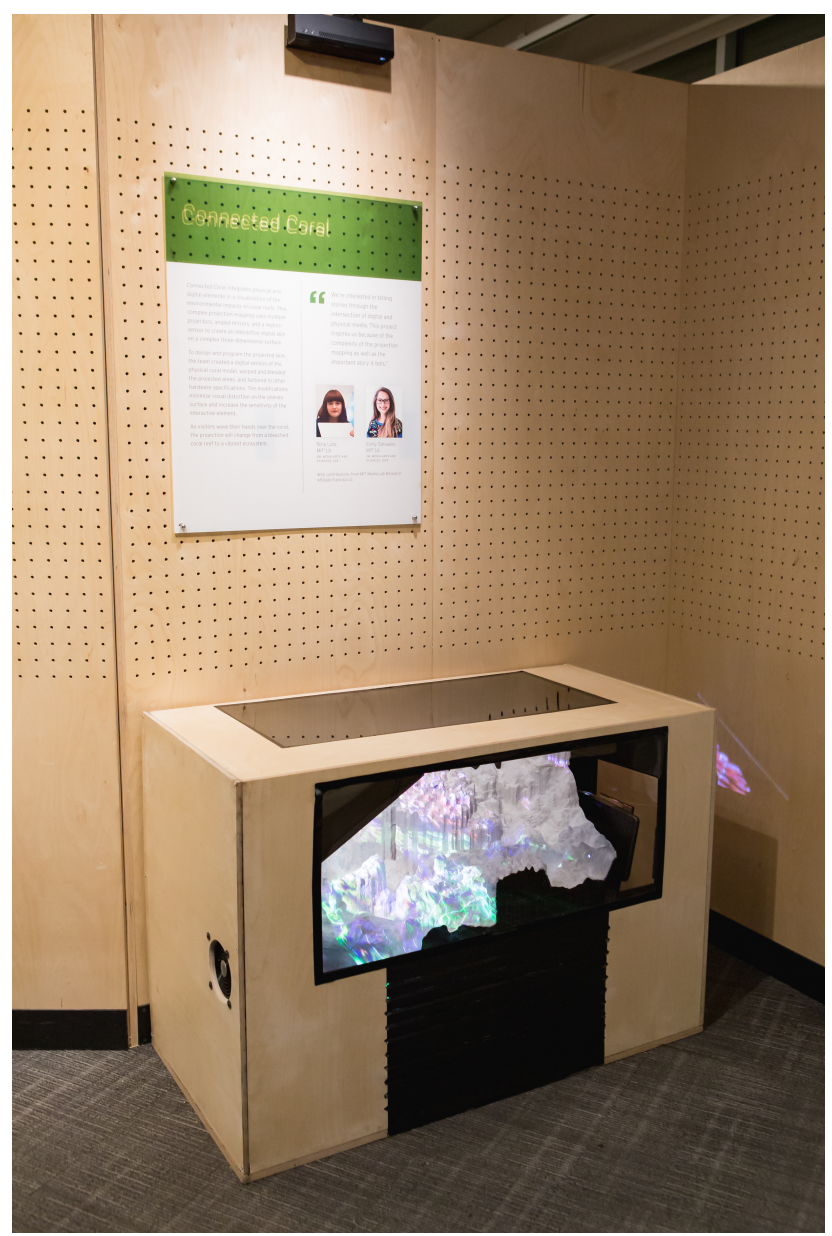

Connected Coral was on display at the MIT Museum for six months in 2018-2019.

To integrate the projected content with the physical design, four different projectors and mirrors were aligned into an enclosure with the reef. The projected areas were warped and blended digitally in order to preserve the colors of the coral attained by The Hydrous along with other educational animations. These modifications minimized visual distortion on the uneven surface and allow for an uninhibited interactive experience.

\section{Successes}

Overall, this project brought an at scale interaction to coral reefs that is hard to replicate in other environments, all at a reasonable cost in a flexible framework that could be applied to different reefs and other underwater environments. Connected Coral was shared with thousands of people on exhibit at the 2018 National Ocean Exploration Forum: All Hands on Deck and at the MIT Museum for 6 months in 2018-2019.

\section{Acknowledgements}

Connected Coral was funded by the MIT Media Lab Open Ocean Initiative and hosted at the MIT Museum. 